\title{
A participação dos pais na carreira das atletas femininas de ginástica artística: a perspectiva dos técnicos
}

CDD. 20.ed. 796.011

796.41

\author{
Myrian NUNOMURA* \\ Mauricio Santos OLIVEIRA**
}

*Escola de Educação

Física e Esporte

de Ribeirão Preto,

Universidade de São

Paulo.

**Escola de Educação

Física e Esporte,

Universidade de São

Paulo.

Este estudo teve por objetivo identificar e discutir como os técnicos de Ginástica Artística avaliam a participação dos pais no desenvolvimento atlético das ginastas nas categorias formativas. Trinta e quatro técnicos que estão distribuídos em 29 instituições do Brasil foram entrevistados. Para o tratamento dos dados utilizamos a técnica de análise de conteúdo proposta por BARDIN. Observou-se que a maioria dos técnicos reconhece a importância da participação dos pais e, assim, busca estabelecer canais de comunicação e aproximação para que os mesmos estejam engajados com o cotidiano dos treinamentos e das competições, bem como cientes das suas atitudes, ações e investimentos que são fundamentais para apoiar o sucesso das ginastas no esporte de competição.

Palavras-chave: Formação esportiva; Participação dos pais; Esporte infantil.

\section{Introdução}

No contexto esportivo a família, os técnicos, os companheiros de equipe e os árbitros formam uma rede social complexa e multidimensional que influencia na qualidade da participação e da experiência esportiva dos jovens atletas ${ }^{1-5}$. E, diante do crescimento da prática esportiva entre crianças e jovens, devemos ter atenção especial à adequação geral dos programas de formação de atletas em todas as dimensões do desenvolvimento humano. Assim, torna-se importante que os pais acompanhem seus filhos, tanto para apoiá-los como para verificar a qualidade dos programas e dos profissionais envolvidos.

Os pais são os responsáveis por apresentar a prática esportiva às crianças e proporcionam os meios e os recursos necessários para que seus filhos se mantenham engajados no esporte ${ }^{6}$.

EWING et al.7 citam que as ações dos pais são determinantes para o estabelecimento de uma experiência positiva dos filhos no esporte. E, conforme FREDRICKS e ECCLES ${ }^{8}$, esses se envolvem de forma pronunciada na vida esportiva dos filhos e desempenham diversos papéis, entre os quais o de técnico, motorista, financiador, espectador e chefe de torcida. Ademais, EDWARDSON e GorelY ${ }^{9}$ ressaltam a influência social significativa dos pais nas atividades físicas dos filhos. Na opinião desses autores, os pais encorajam e influenciam as atitudes dos filhos por meio de suas crenças e ações com relação ao esporte, além de servirem como exemplos.

COGAn e $\operatorname{VIDMAR}^{10}$ atentam para o aspecto de que alguns pais podem prejudicar a carreira dos jovens atletas através de suas açóes. No contexto da GA, NunOMURA ${ }^{11}$ cita que "alguns pais cobram demais seus filhos por resultados, impõem regras alimentares rígidas e chegam até a querer fazer o papel de treinadores dos seus filhos" (p.131). Por essa razão, devemos estar atentos para o modo como os pais apóiam seus filhos no esporte, pois a sua participação é crucial e, por vezes, determinante, tanto para a permanência como para o nível de sucesso na carreira esportiva. Segundo GÁGNE et al. ${ }^{12}$, os pais modelam as experiências esportivas dos filhos e contribuem com a motivação e o autoconceito dos ginastas.

Muitas vezes, as crianças iniciam no esporte com alto nível de motivação e, por falta de incentivo, de apoio e/ou devido ao envolvimento negativo dos pais, elas podem vir a abandonar antes mesmo de atingirem seus objetivos. Por outro lado, aqueles que têm suporte familiar positivo podem permanecer envolvidos no esporte por muito mais tempo do que eles mesmos esperariam. 
Muitos problemas surgem quando não há acordo entre pais e filhos sobre os rumos do envolvimento na prática esportiva, principalmente, de ordem emocional, pois a pressão por resultados e as expectativas irreais podem culminar em uma experiência esportiva negativa para a criança ${ }^{8}$.

HELLSTEDT $^{13}$ apresenta algumas características do comportamento de pais na sua forma de interagir e apoiar a carreira esportiva dos filhos. Segundo o autor, os pais que se envolvem excessivamente são aqueles que discordam e discutem com os técnicos sobre o direcionamento dos treinos, demandam resultados, estão sempre presentes nos treinamentos, mantém expectativas irreais sobre o sucesso esportivo dos filhos e, na maioria dos casos, são famílias super-protetoras e centradas na criança.

Contrariamente e com perfil distinto, estão os pais pouco interessados que são caracterizados pelo envolvimento emocional mínimo, falta de interesse no desenvolvimento atlético, baixo investimento financeiro e pouca ou nenhuma assistência durante os treinos e competições ${ }^{13}$.

Pais com nível moderado de participação são aqueles que, embora sejam grandes apoiadores, são flexíveis na tomada de decisões, estabelecem objetivos compatíveis com as capacidades de seus filhos e mantém uma comunicação aberta, o que facilita a interação entre o técnico e a família do jovem esportista ${ }^{13}$.

Observamos que os pais podem participar da vida esportiva de seus filhos em três níveis diferentes nos quais o comportamento pode ser uma fonte de apoio ou de estresse. Os técnicos devem tentar identificar e compreender as características dos pais e estabelecer estratégias para que o relacionamento entre eles esteja articulado com a proposta do programa. E, assim, contribuam da melhor maneira para que o jovem esportista atinja seus objetivos segundo o seu potencial.

$\mathrm{Na}$ GA, em especial, o papel dos pais pode ser considerado decisivo, pois as crianças iniciam mais cedo do que muitas modalidades competitivas ${ }^{14}$. O fato gera uma dependência maior das crianças em relação aos pais para executar diversas tarefas, tais como: transporte, alimentação, apoio emocional, entre outras. Cogan e VIDMAR ${ }^{10}$ enfatizam que os pais são vitais no bem estar dos jovens ginastas, pois sem o apoio e a assistência parental, tanto emocional como financeira, seria difícil, se não impossível, manter o seu envolvimento na modalidade.

Motivados pelos aspectos supracitados, o presente estudo visa apresentar e discutir como os técnicos avaliam o apoio dos pais no desenvolvimento esportivo das ginastas nas categorias formativas da GA competitiva do Brasil. E, particularmente, identificar os aspectos positivos e negativos desse envolvimento. Embora a literatura aponte a importância do envolvimento dos pais na carreira esportiva de seus filhos, são poucos os estudos que analisaram essa temática na perspectiva daqueles que vivem o cotidiano da modalidade e desenvolvem as jovens ginastas, ou seja, os técnicos.

\section{Método}

Para a coleta de dados utilizamos a entrevista semi-estruturada, pois, essa valoriza a presença do investigador e permite que os sujeitos atinjam a liberdade e a espontaneidade necessárias para o estudo ${ }^{15}$.

Para a seleção dos técnicos, consultamos as federações estaduais a fim de identificar as entidades filiadas que participavam dos torneios oficiais estaduais e nacionais das categorias: pré-infantil, infantil e juvenil.

A participação dos sujeitos foi de caráter espontâneo e, para a conveniência dos técnicos, todas as entrevistas foram realizadas no local de treinamento. Assim, entrevistamos 34 técnicos que atuam na GA feminina em 29 instituições esportivas.

Essas instituições pertencem ao universo de prefeituras municipais, clubes esportivos e academias de GA. Não dispomos de informações que expressem a variabilidade de condições de trabalho e os contextos socioeconômicos onde estão inseridos os técnicos. Consideramos esses aspectos relevantes e que mereceriam atenção em trabalhos futuros, o que ampliaria e corroboraria a presente pesquisa. Entretanto, esses aspectos não integravam o escopo do estudo.

A técnica de análise de conteúdo de BARDIN ${ }^{16}$ foi utilizada para o tratamento dos dados e ocorreu em três etapas: pré-análise, exploração do material e a inferência.

O projeto foi aprovadopelo Comitê de Ética e Pesquisa da Escola de Educação Física e Eporte da Universidade de São Paulo. 


\section{Resultados}

\section{Percepção dos aspectos positivos da participação dos pais}

Para ter sucesso na GA, os ginastas necessitam da assistência dos pais de forma pronunciada ${ }^{10} . \mathrm{Na}$ percepção dos técnicos entrevistados, a formação de associações, o acompanhamento das atividades, o auxílio financeiro e o apoio são ações positivas da participação dos pais na vida esportiva das ginastas (QUADRO 1).

QUADRO 1 - Categoria aspectos positivos.

\begin{tabular}{|c|c|}
\hline Unidade de registro & Unidade de contexto \\
\hline Formação de associaçóes & $\begin{array}{l}\text { T2: [...] tem a Associação de Pais. } \\
\text { T3: [...] associação de pais. }\end{array}$ \\
\hline Auxílio financeiro & $\begin{array}{l}\text { T3: [...] ajuda a gente quanto à estrutura [...] contribuição mensal de } 10 \text { a } 15 \text { reais e a gente } \\
\text { faz eventos, os pais se envolvem pra arrecadaçáo de dinheiro [...] os professores aqui recebem } \\
\text { oito meses da prefeitura e eles ratearam mais dois salários pra trabalhar } 10 \text { e ai dois de férias. }\end{array}$ \\
\hline $\begin{array}{l}\text { Acompanhamento } \\
\text { das atividades }\end{array}$ & $\begin{array}{l}\text { T2: [...] vêm falar com a gente coisas que não estão satisfeitos. Tem bastante apoio. } \\
\text { T5: Eles são super dedicados, sempre vêm na academia perguntam como é que tão } \\
\text { treinando, [...], mas eles tão sempre acompanhando o trabalho, principalmente quando } \\
\text { precisa ajudam bastante, é bem legal. } \\
\text { T13: [...] os pais participam muito. } \\
\text { T25: Boa, boa, tem aquele grupo que vão pras competiçóes. } \\
\text { T12: [...] tem aquele que apóia muito e traz (para o treino). } \\
\text { T27: [...] ajudam bastante, se os pais não tiverem uma luta pra trazer, pra arrumar quem } \\
\text { traga, pra trazer todos os dias, inclusive hoje é feriado e elas estáo treinando [...]. }\end{array}$ \\
\hline Apoio & $\begin{array}{l}\text { T4B: [...] no geral não participam, mas dão apoio se necessário... } \\
\text { T7: [...] bastante incentivo, bastante são bastante perseverantes. } \\
\text { T8: [...] alguns pais dão todo o apoio [...] têm pais que são super positivos. } \\
\text { T12: Apóiam bastante. } \\
\text { T15: [...] ajudam bastante sim. Não tenho problema com pai nenhum. } \\
\text { T17: [...] influenciam bastante, tem os pais que dão super apoio e que tudo que a gente fala } \\
\text { eles topam fazer, topam participar e tem também aqueles que pra eles é um problema você } \\
\text { ter uma coisa, maioria aqui apóia e quer sempre estar, com a criança, o adolescente. } \\
\text { T20: [...] tenho alguns pais que me apóiam muito. } \\
\text { T22B: Apóiam sempre dentro do possível. } \\
\text { T22C: [...] de suma importância, pois sem os pais nenhuma criança estaria aqui fazen- } \\
\text { do. Eles são importantes, dando suporte, tem que ter um contato muito íntimo pra } \\
\text { saber muito da ginasta, você depende muito dos pais. } \\
\text { T23: [...] apoio muito forte dos pais, são parceiros da prefeitura, ajudam muito, } \\
\text { contribuem. } \\
\text { T27: existe uma dedicação muito grande dos pais também, e o apoio deles faz a dife- } \\
\text { rença pro esporte. } \\
\text { T29A: [...] são muito motivadores das crianças, mas vejo que os pais têm muita mais } \\
\text { vontade do que as próprias crianças. }\end{array}$ \\
\hline
\end{tabular}

A formação de associaçôes de pais, citada por T2 e T3 (QUADRO 1), tem por objetivo auxiliar as atividades administrativas, pedagógicas, sociais e a arrecadação de recursos para a manutenção da equipe e da estrutura do ginásio. Os técnicos que entendem essa forma de participação dos pais como positiva citam, com grande frequência, que a associação permite estabelecer um canal de comunicação com os pais. Assim, é possível solucionar muitos problemas do cotidiano, como: apoio financeiro, organização de eventos, uniformes, entre outros.

O auxílio financeiro foi citado pelos técnicos como uma intervenção positiva. Com esse auxílio, os pais complementam o salário dos técnicos e contribuem para a manutenção do ginásio, dos aparelhos e dos equipamentos auxiliares. $\mathrm{O}$ fato é evidenciado 
no discurso de T3, no qual o técnico cita que: “[...] os pais se envolvem pra arrecadação de dinheiro [...] os professores aqui recebem oito meses da prefeitura e eles ratearam mais dois salários [...]".

Muitos técnicos relataram o apoio que os pais proporcionam aos filhos e que alguns deles não medem esforços para resolver problemas ou motivarem as ginastas: "[...] dão apoio se necessário" (T4B); "[...] bastante incentivo." (T7); "Apóiam bastante." (T12); “[...] dão super apoio [...]" (T17); "Apóiam sempre dentro do possível." (T22B); “[...] apoio muito forte dos pais, são parceiros [...]" (T23). JowETT e TimSON-KATCHIS ${ }^{4}$ citam que esse apoio pode ser evidenciado pela aprovação, incentivo, valorização e empatia dos pais.

Outra forma de participação dos pais, elencada pelos técnicos, está relacionada ao acompanhamento das atividades: "[...] tem aquele grupo que vão pras competições" (T25); "[...] se os pais não tiverem uma luta pra trazer, pra arrumar quem traga, pra trazer todos os dias, inclusive hoje é feriado e elas estão treinando [...]" (T27); "Eles são super dedicados, sempre vem na academia perguntam como é que tão treinando, [...], mas eles tão sempre acompanhando o trabalho [...]" (T5).

No estudo de WeISS e HAYASHI ${ }^{17}$, os autores citam que $70 \%$ dos pais de ginastas sentem que sua vida familiar gira em torno das atividades relacionadas à prática da GA. $\mathrm{O}$ transporte para os treinos, participar das competições, acompanhar as atividades do ginásio e buscar informações sobre o desenvolvimento atlético dos filhos são algumas dessas ações.

\section{Percepção de aspectos negativos da participação dos pais}

No processo de formação esportiva, CANDEIAS ${ }^{18}$ discute que, em muitos casos, são os pais que definem o rumo esportivo das crianças que, em determinadas situaçōes, sequer são consultadas sobre suas preferências.

Aqueles que entendem a participação dos pais como negativa relataram que eles intervêm demasiadamente e, consequentemente, atrapalham a evolução das ginastas e, não raras vezes, a necessidade de afastá-los torna-se inevitável. Fatos como o interesse financeiro, o conflito entre os pais das atletas, a falta de interesse pela carreira esportiva, o pouco contato e outros interesses em detrimento da participação esportiva das filhas emergiram do discurso dos técnicos (QUADRO 2). Nessa categoria também foi incluída a atitude dos técnicos de impor limites aos pais e não permitir a sua participação.

QUADRO 2 - Categoria aspectos negativos.

\begin{tabular}{|c|c|}
\hline Unidade de registro & Unidade de contexto \\
\hline Interesse financeiro & $\begin{array}{l}\text { T10A: [...] ela é pior por causa da família, os pais não trabalham mais, pararam de traba- } \\
\text { lhar. [...] entáo, tudo é em função dela. }\end{array}$ \\
\hline Conflitos entre os pais & $\begin{array}{l}\text { T4A: Essas três disputam entre elas e temos problemas. } \\
\text { T10B: Teve criança que saiu em funçáo do grupo de pais. O grupo mais novo os pais ficam de } \\
\text { fofocas e tivemos que selecionar no pré-time... as três que sobraram os pais tiraram do clube! }\end{array}$ \\
\hline Falta de apoio & $\begin{array}{l}\text { T4B: [...] maioria é indiferente, gostaria que eles participassem mais... } \\
\text { T10A: classe média e burguesia não está se predispondo a não ter férias... estão batendo na } \\
\text { qualidade de vida sempre. Quem tem grana quer realmente descansar no meio do ano, ter } \\
\text { seu feriado. E tem treinamento de dois turnos, 2a à sábado, não tem feriado, e muita família } \\
\text { não está se predispondo. Hoje é aula de inglês, computação, computador, sapateado... } \\
\text { T26: Na hora em que precisamos deles mesmo, só meia dúzia. } \\
\text { T29B: [...] chega aqui tem que vir todos os dias, aí a criança faz inglês, faz, sabe, outra faz } \\
\text { algum outro esporte, ou faz piano, aí os pais não querem, às vezes seguram também. }\end{array}$ \\
\hline Apoio com restriçóes & $\begin{array}{l}\text { T4A: Uns ajudam e outros atrapalham. } \\
\text { T8: [...] dão todo o apoio com pressão demais. } \\
\text { T26: Ver os pais que apóiam e criticam... Tem todo tipo de pai. }\end{array}$ \\
\hline Pouco contato & $\begin{array}{l}\text { T8: Alguns são meio afastados, eles não são nem positivos nem negativos, mas isso às } \\
\text { vezes é ruim também, porque se mantém totalmente alheios ao que está acontecendo. } \\
\text { T10B: Tenho que chamar os pais se quiser conversar senão não aparecem nunca. } \\
\text { T17: [...] a gente nem conhece (os pais), porque, assim, vêm desacompanhados ou vêm } \\
\text { acompanhados de babás ou alguma pessoa. } \\
\text { T22A: [...] não tenho problema nenhum com os pais, eles não aparecem aqui, só mandam recados. } \\
\text { T29C: [...] não tem problema nenhum, são bem neutros... é bem neutro. }\end{array}$ \\
\hline
\end{tabular}


QUADRO 2 - Categoria aspectos negativos (continuação).

\begin{tabular}{|l|l|}
\hline Unidade de registro & Unidade de contexto \\
\hline & T6: $[\ldots]$ aqueles pais que podem atrapalhar a gente fica atenta e póe limite pra eles. \\
& T10B: $[\ldots]$ esse grupo é extremamente neutro, mas também não ajuda em nada. \\
Técnicos não buscam & T11: [...] não deixamos assistir todas aulas, só a última do mês, pra não ter problemas. \\
interagir, não oferecem & T16A: $[\ldots]$ tenho super pouco contato. \\
abertura, impóem & T16B: $[\ldots]$ pais não podem entrar, tem que liberar o acesso, atendemos fora, mas não interfere. \\
limites & T18: $[\ldots]$ tento não ter muito contato. \\
& T19: $[\ldots]$ contato é bem pouco. \\
& T24: $[\ldots]$ evito o contato. \\
\hline
\end{tabular}

$\mathrm{Na}$ GA brasileira, é fato recente que o reconhecimento do mérito seja pela compensação financeira. E, como tem sido muito difundido na mídia, reforça-se entre os pais a ideia de que poderá haver retorno de seu investimento na modalidade.

Quando esporte e dinheiro se unem, é preciso muita atenção para que o segundo não se torne o objetivo e a razão do envolvimento, conforme podemos observar no discurso de T10A: “[...] os pais não trabalham mais, pararam de trabalhar. [...] então, tudo é em função dela (ginasta)". Tofler e BUTTERBAUGH ${ }^{19}$ afirmam que jovens desfavorecidos, econômica e culturalmente, vêem no esporte um passaporte para mudar seu "status" na sociedade. Segundo os autores, nesses casos os pais depositam suas expectativas e seu bem-estar financeiro nos filhos, o que eleva a pressão sobre o jovem atleta. Segundo o técnico T10A, os pais da atleta pararam de trabalhar e dependem, financeiramente, dela. WuerTH et al. ${ }^{20}$ afirmam que há casos de pais, com envolvimento ativo na carreira dos filhos, que sugerem que eles restituam o investimento de tempo, esforço e dinheiro na promoção de sua carreira esportiva.

A disputa entre os pais das ginastas, embora citado com menor expressão, merece atenção, pois esse atrito pode influenciar o comportamento das atletas no ginásio e dificultar a união da equipe e, em alguns casos, motivar a saída de algumas delas: "Teve criança que saiu em função do grupo de pais [...]” (T10B). Essa situação ocorre, na maioria das vezes, por ciúmes, principalmente, no momento da seleção das ginastas para compor a equipe, conforme foi citado nos discursos de T4A e T10B: "Essas três disputam entre elas e temos problemas" (T4A); "[...] O grupo mais novo os pais ficam de fofocas e tivemos que selecionar no pré-time... as três que sobraram os pais tiraram do clube!" (T10B).

A falta de apoio foi outro fator mencionado nas entrevistas. A indiferença pela prática esportiva dos filhos e outros interesses foram alguns dos temas discutidos pelos técnicos: “[...] maioria é indiferente, gostaria que eles participassem mais" (T4B); "tem treinamento de dois turnos, segunda a sábado, não tem feriado e muita família não está se predispondo" (T10A).

HellstedT $^{13}$ cita que os pais que se envolvem pouco na prática esportiva demonstram o mínimo de interesse em discutir o desenvolvimento atlético do filho com o técnico, raramente participam de competições e demais campos, como emocional, financeiro ou funcional. Verificamos que os pais que usufruem melhor condição financeira incubem motoristas e babás para acompanharem os filhos nos treinos e competições e, assim, ampliam o seu distanciamento dessas atividades: "[...] a gente nem conhece (os pais), porque, assim, vêm desacompanhados ou vêm acompanhados de babás ou alguma pessoa” (T17).

Constatamos que embora haja pais que se abstêm de participar na vida esportiva dos filhos, outros são atuantes, mas, na opinião dos técnicos, com muitas expectativas e críticas, o que pode estressar as ginastas. Os sujeitos citam que a pressão pode resultar em "dropout", opinião corroborada por SACKS et al. ${ }^{21}$ e MAgEAU et al. ${ }^{22}$. Os técnicos relataram que impõem certos limites para que os pais não excedam na sua participação: "[...] aqueles pais que podem atrapalhar a gente fica atenta e põe limite pra eles" (T6); “[...] não deixamos assistir todas as aulas, só a última do mês, pra não ter problemas” (T11); “[...] pais não podem entrar, têm que liberar o acesso, atendemos fora, mas não interfere" (T16).

Outros técnicos mencionaram o pouco contato com os pais e, por isso, não enfrentam problemas de relacionamento, pois os mesmos se mantêm afastados: "[...] contato é bem pouco" (T19); “[...] tenho super pouco contato” (T16A); “[...] esse grupo é extremamente neutro [...]” (T10B). Na opinião dos técnicos essa neutralidade é negativa, pois estes estão alheios ao que está acontecendo na vida esportiva das ginastas: "Alguns são meio afastados, eles não são nem positivos nem negativos, mas isso às vezes 
é ruim também, porque se mantém totalmente alheios ao que está acontecendo" (T8). Eles citam que o pouco contato é por desinteresse dos pais e não deles técnicos: "Tenho que chamar os pais se quiser conversar senão não aparecem nunca” (T10B). Um dos técnicos afirmou que até convoca os pais quando há problemas mais sérios, mas, poucos comparecem.

HELLSTEDT $^{13}$ atenta para o fato de que os atletas de pais desinteressados, principalmente, aqueles que sentem falta de apoio emocional e funcional, terão problemas em seguir na carreira esportiva. E, possivelmente, esses indivíduos terão maior probabilidade de abandonar o esporte.

\section{Discussão}

O envolvimento de crianças no esporte é permeado por ações adultas que, na opinião de KORSAKAS ${ }^{23}$, interferem de forma significativa nas experiências esportivas dos praticantes.

Os pais, técnicos, dirigentes e árbitros agem, direta ou indiretamente, nas experiências esportivas. Essas interferências definem o ambiente no qual as crianças interagem e têm alto potencial benéfico, mas, em algumas situaçôes, podem ser prejudiciais ao processo de formação dos atletas ${ }^{24}$.

O envolvimento dos pais é crucial para o desenvolvimento de atletas de alto nível, pois eles podem propiciar um ambiente favorável ao engajamento das crianças na prática de esportes ${ }^{25}$.

O apoio literário para a atuação dos pais e sua importância na carreira esportiva dos filhos é inquestionável e sua participação compreende uma gama de afazeres. WeIss e HAYASHI ${ }^{17}$ citam que os pais influenciam a carreira esportiva de seus filhos por meio de diferentes ações, como: encorajar, acompanhar os treinos, participar de eventos competitivos, investir tempo e dinheiro, conhecer o esporte que a criança pratica e organizar a rotina da família de acordo com as necessidades da prática esportiva de seus filhos. Em complementação, SouzA-Uva ${ }^{26}$ cita que os pais

Transportam os filhos e respectivos colegas para os treinos e as competições, participam em reuniōes de angariação de fundos para a época desportiva, pagam uma mensalidade, vendem rifas aos colegas de trabalho, participam na elaboração ou compra de equipamentos desportivos, participam de festas-convívios promovidas pelos clubes, seguem e apóiam incansavelmente os filhos nas competiçōes, onde quer que estas se realizem, exigem
Talvez, motivados por problemas e experiências anteriores, alguns técnicos, como, T18 e T24, não buscam o contato com os pais e declaram, respectivamente, que evitam qualquer aproximação: "[...] tento não ter muito contato"; "[...] evito o contato". Isso contradiz a literatura, pois, a participação e o apoio dos pais são essenciais na vida esportiva das crianças e independente do nível de habilidade. Certamente, a perda maior nessa situação é da própria criança e do técnico que poderiam ter um aliado, principalmente, nas instituições privadas, pois os pais são aqueles que mantêm o esporte através de taxas e do consumo de serviços.

competência e pedagogia da parte dos técnicos e responsabilidade da parte dos clubes, vigiam regularmente a saúde desportiva dos seus educandos, motivam-se mutuamente, angariam patrocínios e até chegam a agregar-se para formar os corpos sociais dos clubes (p.34).

Como esperávamos, a percepção dos técnicos sobre a participação dos pais apresenta dois pólos bem distintos: positivo ou negativo. E, ainda que muitos declarassem a participação dos pais como neutra, observamos que havia tendência para um dos pólos.

Há consenso na literatura sobre a importância dos pais na vida esportiva de seus filhos ${ }^{18,27-30}$. E, muitos técnicos têm consciência do fato e buscam criar canais de comunicação com os pais para que eles estejam cientes do cotidiano dos treinos e das competições. No relato dos técnicos, esse aspecto ficou evidente quando eles citam a criação de associação de pais (T2, T3), as reuniōes (T2, T10B, T16B) e a liberdade para que os pais possam buscar o diálogo com os técnicos (T5). O que é favorável para a evolução das atletas.

Em muitos casos, os pais mediam o relacionamento entre atletas e técnicos, pois, muitas crianças apresentam dificuldades para se comunicar diretamente com os técnicos e não manifestam seu sentimento, preocupação ou solicitam esclarecimentos: "[...] Eles são importantes, dando suporte, tem que ter um contato muito íntimo pra saber muito da ginasta, você depende muito dos pais" (T22C).

A formação de uma associação de pais para solucionar problemas financeiros, a confecção de uniformes e, em um dos casos, pagar os salários dos técnicos foi percebida como participação positiva 
dos pais. $\mathrm{O}$ apoio financeiro reflete-se nas atividades para arrecadar fundos. Isso ocorre através de bingos, festas, cantinas, por exemplo, e expressam a preocupação e o esforço de pais a fim de oferecer condições adequadas para que seus filhos possam competir ou garantir o material necessário para o treinamento.

Alguns técnicos relataram que muitos pais apóiam "demais": "[...] Tem bastante apoio" (T2); "Eles são super dedicados, [...] tão sempre acompanhando o trabalho, principalmente, quando precisa, ajudam bastante, é bem legal" (T5); [...] os pais participam muito" (T13). É importante ressaltar que a abertura aos pais é necessária, mas pode ser prejudicial se eles intervierem além de seus limites, como: assistir a todos os treinos, opinar sobre as condutas dos técnicos, interferir sobre quem deve compor a equipe nas competições e eventos.

Essas atitudes acabam criando atritos e anulam o potencial de apoio dos pais ${ }^{31}$. KANTERSET al. ${ }^{32}$ explicitam que alguns pais têm dificuldade em perceber que o seu grau de envolvimento na carreira atlética dos filhos pode ser entendido, em certos casos, como fonte de estresse para os jovens atletas. E, pode ser crítico quando cobram ou pressionam os filhos por resultados e vitórias.

Sabemos que os pais exercem grande influência sobre as emoções das crianças no esporte ${ }^{33}$. Eles podem gerar níveis de ansiedade significativos nas crianças, principalmente, em situações précompetitivas e competitivas que resultariam em consequências desfavoráveis ao desenvolvimento esportivo e emocional delas ${ }^{30,34-35}$. RoBbins ${ }^{36}$ relacionou fatores em potencial que causariam estresse em jovens esportistas, que podem estar relacionados, direta ou indiretamente, aos pais, como críticas, comentários, pressões e expectativas.

Quando as crianças percebem o nível elevado de expectativa dos pais sobre os resultados do seu desempenho esportivo, elas podem desenvolver níveis de ansiedade, apreensão, desapontamento ou desaprovação nos momentos não bem sucedidos. Esse estado pode comprometer a sua autoconfiança e a percepção de sua competência e, por vezes, levar ao abandono da prática esportiva.

No estudo de GONÇALVES ${ }^{37}$ foi constatado que 90\% dos jovens entre 14 e 15 anos de idade abandonaram o esporte, com média de participação em competições de 3,1 anos. E, um dos fatores relacionados ao abandono foi a pressão dos pais. MAGEAU et al. ${ }^{22}$ citam que o estresse e o "burnout "podem estar relacionados ao exagero dos pais na sua forma de apoiar a prática esportiva de seus filhos. Esse excesso de envolvimento não se traduz apenas em tempo de dedicação à carreira atlética dos filhos. E, WEISS e HAYASHI ${ }^{17}$ sugerem que a diferença entre o envolvimento positivo e negativo dos pais está na qualidade desse envolvimento. Quando os pais são encorajadores, entusiastas e positivos as respostas das crianças também são igualmente favoráveis ${ }^{33}$.

Como podemos observar, os pais são agentes motivadores ou agentes de pressão ${ }^{29}$. $\mathrm{Na}$ opinião de $\mathrm{NASH}^{31}$ é comum que pais e técnicos exijam esforço dos jovens atletas para que eles atinjam a perfeição e que essa pressão, talvez, seja responsável por doenças físicas e psicológicas. Segundo o autor, o velho provérbio "não importa se você vence ou perde, mas como você participa", (que deveria ser o lema dos pais), caiu em desuso. E, muitos profissionais da área da Saúde e da Psicologia do Esporte alegam que as mudanças na sociedade nos últimos anos criaram condições que justificam o fato, principalmente, em modalidades individuais em que a vida esportiva inicia em tenra idade. $\mathrm{Na}$ GA, em especial, a ansiedade por resultados pode ser ainda mais evidente, pois como as crianças iniciam muito jovens na modalidade, a forma e o grau de envolvimento dos pais são acentuados.

A distância que alguns técnicos preferem manter dos pais pode ser justificada pelo excesso de intervenção desses ou pelo potencial de cobranças. Alguns técnicos citaram que sequer conhecem os pais, pois, além de não criarem um canal de comunicação, muitas vezes, as crianças são acompanhadas por terceiros, conforme observamos no depoimento de T17 (QUADRO 2).

MCCALlister et al. ${ }^{38}$ citam a influência da pressão que os pais exercem sobre os técnicos e que, muitas vezes, são opostos aos objetivos da participação de crianças e de jovens no esporte, pois, muitos enfatizam as vitórias em detrimento da aprendizagem e da formação de seus filhos. Por outro lado, a indiferença demonstrada por meio do pouco contato ou a falta de apoio dos pais, expostas nos discursos de T29B, T26, T10A, T4B, T8, T17, T22A, T10B e T29C, pode gerar insegurança para algumas crianças, pois é uma fase em que elas necessitam de aceitação e aprovação para a construção de sua autoestima e autoconfiança ${ }^{39-40}$. Os técnicos podem contribuir nesse caminho, mas, jamais poderão substituir o papel dos pais na vida das crianças ${ }^{13}$.

Em muitos casos, a atitude dos pais pode ser decisiva no sucesso da vida esportiva das crianças $^{28,41}$. Essas dependem dos pais para se deslocarem, da compreensão deles quando há eventos nos finais de semana e feriados ${ }^{26}$, do incentivo financeiro, do apoio emocional em momentos de frustração ou ansiedade, 
de cuidados com a alimentação, entre outros. Caso as crianças não encontrem o apoio da família, ainda que apresente muito talento, poderá ser uma barreira muito difícil de ser superada. Isso fica explícito nos discursos de T22C e T27, respectivamente: “[...] (o apoio é) de suma importância, pois sem os pais nenhuma criança estaria aqui fazendo (GA)"; "[...] o apoio deles faz a diferença pro esporte".

Ainda que alguns pais assumam uma postura negativa frente à vida esportiva de seus filhos, os técnicos devem se esforçar para estabelecer um canal satisfatório de comunicação e procurar a aproximação deles, sem cobrar ou pressionar, mas orientar sobre a importância de sua participação e estar ciente de que a criança necessita do seu apoio.

Percebemos no decorrer do estudo que a participação dos pais na vida esportiva dos filhos ainda é um tema pouco explorado, investigado e, consequentemente, pouco compreendido pelos técnicos e pela Pedagogia do Esporte. Tampouco, parece ser o interesse de alguns adultos envolvidos diretamente no cotidiano do esporte em entender e compartilhar com os pais a responsabilidade pelo desenvolvimento das crianças.

SIMŌES et al. ${ }^{27}$ questionam qual seria a forma adequada e o grau de participação que os pais deveriam ter para apoiar a vida esportiva dos filhos. Conforme observamos na literatura e no estudo de campo, não há dúvidas sobre a importância e a influência dos pais na vida esportiva de seus filhos. Da mesma forma, está claro que sem o relacionamento positivo entre técnicos e pais o prejuízo maior será dos filhos. Compartilhamos com Hellsted $T^{13}$ o pensamento que os técnicos não lidam apenas com os seus atletas, mas, com toda a família. E, ao negligenciar o fato, poderão prejudicar não somente os jovens esportistas, mas, todo o programa esportivo.

Apesar de ser notório o impacto da participação dos pais na carreira das ginastas, há incertezas sobre como técnicos e pais poderiam compartilhar as responsabilidades para criar um ambiente saudável e incentivador às crianças e os jovens atletas, de modo que não houvesse envolvimento excessivo ou negligência total.

O equilíbrio parece ser o melhor caminho, mas, também, o ponto mais difícil de ser atingido sem o esforço, a compreensão e a cooperação mútua entre pais e técnicos.

Talvez, um caminho para o sucesso no esporte seja a orientação ou um manual para os pais e técnicos, de modo a desenvolver um convívio harmonioso e articulado que coincidam em favor da qualidade da experiência esportiva dos jovens esportistas. E, esse trabalho pode ser a chave para o sucesso no alto rendimento.

Caso os pais estejam conscientes de seu papel na vida esportiva de seus filhos e saibam lidar com a diversidade de situações inerentes ao esporte, quiçá o sucesso possa ser interpretado de outras formas que não somente resultados e vitórias. E assim, as experiências, as amizades, o desenvolvimento geral e, principalmente, o prazer sejam as principais conquistas da participação no esporte.

Estamos cientes de que o trinômio técnicos-paisginastas deveria ser explorado em diversas dimensóes e em suas inter-relações, de modo que pudéssemos compreender o fenômeno em suas diferentes perspectivas. Assim, estudos subsequentes poderiam investigar a percepção de pais sobre a atuação de técnicos e de seus filhos, por exemplo.

\begin{abstract}
The parents' involvement in the career of female artistic gymnasts: the coaches' perspectives

This study aimed to identify and discuss how the Artistic Gymnastics coaches perceive the parent's participation on gymnasts sport development in the formative years. Thirty four coaches from 29 sport institutions in Brazil were interviewed. The content analysis technique proposed by BARDIN was adopted for data treatment. The results showed that most coaches are aware of the importance of parental involvement and, therefore, they try to establish ways of communication and approaching to ensure that parents are engaged in the daily workouts and competitions, as well as aware of their attitudes, actions and investments that are crucial to support the gymnasts' success at competitive sport.
\end{abstract}

KEY wORDS: Sport development; Parental support; Youth sports. 


\section{Referências}

1. Côté J. The influence of the family in the development of talent in sport. Sport Psychol. 1999;13:395-417.

2. Côté J, Hay J. Family influences on youth sport participation and performance. In: Silva J, Stevens D, organizadores. Psychological foundations of sport. Boston: Allyn and Bacon; 2002.

3. Brustad RJ, Partridge JA. Parental and peer influence on children's psychological development through sport. In: Smoll FL, Smith RE, organizers. Children and youth in sport: a biopsychosocial approach. Dubuque: Kendall/Hunt; 2002.

4. Jowett S, Timson-Katchis M. Social networks in sport: the influence of parents on the coach-athlete relationship. Sport Psychol. 2005;19:267-87.

5. Weiss WM, Weiss MR. Sport commitment among competitive female gymnasts: a developmental perspective. Res Q Exerc Sport. 2007;78:90-102.

6. Fraser-Thomas J, Côté J, Deakin J. Understanding dropout and prolonged engagement in adolescent competitive sport. Psychol Sport Exerc. 2008;9:645-62.

7. Ewing ME, Gano-Overway LA, Branta CF, Seefeldt VD. The role ofsports in youth development. In: Gatz M, Messner MA, Ball-Rokeach SJ. Paradoxes of youth and sport. Albany: Suny; 2002. p.31-48.

8. Fredricks JA, Eccles JS. Parental influences on youth involvement in sports. In: Weiss MR, editor. Developmental sport psychology: a lifespan perspective. Morgantown: Fitness Information Technology; 2004.

9. Edwardson CL, Gorely T. Parental influences on different types and intensities of physical activity in youth: a systematic review. Psychol Sport Exerc. 2010;11:522-35.

10. Cogan KD, Vidmar P. Gymnastics. Morgantown: Fitness Information Technology; 2000.

11. Nunomura M. Ginástica artística. São Paulo: Odysseus; 2008.

12. Gágne M, Ryan R, Bargmann K. Autonomy support and need satisfaction in the motivation and well-being of gymnasts. J Appl Sport Psychol. 2003;15:372-90.

13. Hellstedt JC. The coach/parent/athlete relationship. Sport Psychol. 1987;1:151-60.

14. Filin VP, Volkov VM. Seleção de talentos nos esportes. Londrina: Miograf; 1998.

15. Triviños ANS. Introdução à pesquisa em ciências sociais: a pesquisa qualitativa em educação. São Paulo: Atlas; 1987.

16. Bardin L. Análise de conteúdo. Lisboa: Ediçōes 70; 2010.

17. Weiss MR, Hayashi CT. All in family: parent-child influences in competitive youth gymnastics. Pediatr Exerc Sci. 1995;7:36-48.

18. Candeias JG. Crianças e formação desportiva. Treino Desport. 1998;1:3-10.

19. Tofler IR, Butterbaugh GJ. Developmental overview of child and youth sports for the twenty-first century. Clin Sports Med. 2005;24:783-804.

20. Wuerth S, Lee MJ, Alfermann D. Parental involvement and athletes' career in youth sport. Psychol Sport Exerc. 2004;5:21-33.

21. Sacks DN, Tenenbaum G, Pargman D. Providing sport psychology services to families. In: Dosil J, organizer. The sport psychologist's handbook: a guide for sport-specific performance enhancement. Chichester: John Wiley \& Sons; 2006.

22. Mageau RJ, Vallerand RJ, Charest J, et al. On the development of harmonious and obsessive passion: the role of autonomy support, activity specialization, and identification with the activity. J Pers. 2009;77:601-45.

23. Korsakas P. O esporte infantil: as possibilidades de uma prática educativa. In: De Rose Junior, D. Esporte e atividade física na infância e na adolescência: uma abordagem multidisciplinar. Porto Alegre: Artmed; 2002.

24. Vilani LHP, Samulski DM. Família e esporte: uma revisão sobre a influência dos pais na carreira esportiva de crianças e adolescentes. In: Silami-Garcia E, Lemos KLM, organizadores. Temas atuais VII: educação física e esportes. Belo Horizonte: Health; 2002.

25. Bloom BS, organizer. Developing talent in young people. New York: Ballantine; 1985.

26. Souza-Uva JE. Aspectos a considerar na relação com os pais dos atletas: o papel dos pais no atletismo para jovens. Treino Desport. 2005;7:34-42.

27. Simões AC, Böhme MTS, Lucato S. A participação dos pais na vida esportiva dos filhos. Rev Paul Educ Fís. 1999;13:34-45.

28. Baxter-Jones AD, Maffulli N. Parental influence on sport participation in elite young athletes. J Sports Med Phys Fitness. 2003;43:250-5.

29. Roffé M, Fenili A, Giscafré N. Mi hijo el campeón: las presiones de los padres y el entorno. Bueno Aires: Lugar Editorial; 2003.

30. Nunomura M, Araújo CM, Ferreira-Filho R. Stress pré-competitivo na ginástica artística feminina. Treino Desport. 2005;7:4-13. 
31. Nash HL. Elite child-athletes: how much does victory cost? Phys Sportsmed. 1987;15:128-33.

32. Kanters MA, Bocarro J, Casper JM. Supported or pressured? An examination of agreement among parents and children on parent's role in youth sports. J Sport Behav. 2008;31:1-17.

33. Hedstrom R, Gould D. Research in youth sports: critical issues status. Michigan: Michigan State University; 2004.

34. Scanlan TK, Lewthwaite R. Social psychological aspects of competition for male youth sport participants: I. Predictors of competitive stress. J Sport Psychol. 1984;6:208-26.

35. Rose Júnior D, organizador. Esporte e atividade física na infância e na adolescência: uma abordagem multidisciplinar. Porto Alegre: Artmed; 2002. p.77-87.

36. Robbins JE. Reducing stress: techniques for parents, coaches, and athletes. Spotlight Youth Sports. 2001;25:1-3.

37. Gonçalves C. Um olhar sobre o processo de formação do jovem praticante. Treino Desport. 1999;2:42-8.

38. McCallister SG, Blinde EM, Weiss WM. Teaching values and implementing philosophies: dilemmas of the youth sport coach. Phys Educ. 2000;57:35-44.

39. Bee H. A criança em desenvolvimento. Veronese MAV, tradutora. 7a ed. Porto Alegre: Artes Médicas; 1996.

40. Newcombe N. Desenvolvimento infantil: abordagem de Mussen. Buchweitz C, tradutor. Porto Alegre: Artmed; 1999.

41. Araújo D. Para vencer a competição de valores. Treino Desport. 2005;7:60-5.

\section{Agradecimentos}

Os autores agradecem o apoio da FAPESP, $n^{\circ}$ processo 2003/12725-8.

\begin{tabular}{r|l} 
ENDEREÇo & \\
Myrian Nunomura & \\
Escola de Educação Física e Esporte de Ribeirão Preto & Recebido para publicação: 20/o1/2012 \\
Universidade de São Paulo & 1a. Revisão: 25/08/2012 \\
Av. Bandeirantes, 3900 & 2a. Revisão: 05/12/2012 \\
14040-907 - Ribeirão Preto - SP - BRASIL & 3a. Revisão: 23/04/2013 \\
e-mail: mnunomur@usp.br & Aceito: 18/o6/2013
\end{tabular}

134 • Rev Bras Educ Fís Esporte, (São Paulo) 2014 Jan-Mar; 28(1):125-34 